\title{
COMMENTARY
}

\section{A Call to Action for Lactation Support at Colleges of Pharmacy}

\author{
Mary E Fredrickson, PharmD, Jaclyn Boyle, PharmD, MS, M. Petrea Cober, PharmD, Cynthia A King, PharmD
}

Corresponding Author: Mary E. Fredrickson, Northeast Ohio Medical University, College of Pharmacy, 4209 State Rt 44, Rootstown, Ohio, 44272. Tel: 330-325-6326. Email: mfredrickson@neomed.edu

Submitted April 16, 2021; accepted October 19, 2021; ePublished November 2021

The promotion of faculty wellbeing has been emphasized in recent years, with the Academy implored to develop and implement strategies to minimize stress and burnout among its members. Among those at highest risk of succumbing to burnout are female faculty, particularly those with young children. There are numerous work-life issues that predispose this cohort to stressors. One specific, important area of consideration is the provision of lactation support in the workplace. Responding to the broader directive to promote faculty wellbeing, the aim of this commentary is to stimulate conversation regarding the provision of lactation support at colleges of pharmacy. Establishing such services has the potential to improve the personal and professional wellbeing of female faculty who are breastfeeding while also eliciting institution-wide advantages. This article discusses the benefits of breastfeeding, highlights the personal, professional, and institutional ramifications of breastfeeding discrimination, and summarizes best practices related to implementation of lactation support services.

Keywords: women, faculty, wellbeing lactation support

\section{INTRODUCTION}

Within academic pharmacy there has been a renewed focus on faculty wellbeing, with the Academy implored to develop and implement strategies to prevent and reduce stress and burnout among its members. ${ }^{1}$ Such an initiative is imperative, as failure to address underlying causes of burnout has implications ranging from decreased faculty retention and recruitment to higher rates of depression and suicidality. ${ }^{1}$ Strategically, it has been suggested to focus attention on faculty at highest risk, which includes female faculty and those with young children. ${ }^{2}$ There are numerous work-life issues that predispose this cohort to stressors, and many considerations could be made regarding implementation of much needed family-friendly support measures. One specific, important area of consideration is the provision of lactation support in the workplace. ${ }^{3}$ Responding to the broader directive to promote faculty wellbeing, the aim of this commentary is to stimulate conversation regarding the provision of lactation support at colleges of pharmacy. This article discusses the benefits of breastfeeding, highlights the personal, professional, and institutional ramifications of breastfeeding discrimination, and summarizes best practices related to implementation of lactation support services. The terms "lactating" and "breastfeeding" are used interchangeably.

\section{Personal and Professional Implications of Breastfeeding Discrimination for Women in Academia}

The World Health Organization (WHO) and the American Academy of Pediatrics (AAP) recommend breastfeeding as the sole source of nutrition in infants less than six months of age and continued breastfeeding with supplemental nutrition for at least one (AAP) to two years (WHO) or longer if desired by mother and baby. ${ }^{4,5}$ The benefits of breastfeeding extend beyond nutritional qualities and for infants include a lower risk of developing type II diabetes mellitus, asthma, otitis media, and respiratory infections. ${ }^{5}$ Breastfeeding mothers also experience health benefits. These include a reduced risk of developing rheumatoid arthritis, osteoporosis, and breast and ovarian cancer. ${ }^{4,5}$ Improvements in mental health include reductions in anxiety, stress levels, and postpartum depression. ${ }^{6}$

Despite overwhelming evidence related to the advantages of breastfeeding, challenges to sustain the process are substantial, and the associated implications for lactating mothers are pertinent to women in academic pharmacy. Women comprise a growing percentage of pharmacy graduates entering the workforce, and in 2020 they earned approximately 63 percent of first professional degrees. ${ }^{7}$ In the academic setting, the most recent data find women make up 37 percent of professors, 53 percent of associate professors, and 60 percent of assistant professors. ${ }^{8}$ As many of these women may enter motherhood at some point in their careers, it is vital the challenges faced as they attempt to balance the responsibilities of work and family are appropriately addressed.

Barriers that arise for lactating pharmacy faculty have not been reported but are likely congruent with those of other working lactating mothers. Of primary significance is the lack of mandated paid maternity leave within the United 
States. ${ }^{9}$ Currently, the Family and Medical Leave Act obligates employers with more than 50 employees to offer 12 weeks of unpaid leave for mothers of newborns. ${ }^{10}$ Due to this limited leave, a proportion of female faculty may return to work at a time during which they will need to express breastmilk ("pump") to maintain their breastfeeding relationships. In addition, a lack of paid leave may be a compelling financial reason for mothers to return to work as soon as possible. In some instances, faculty may find themselves returning to work before their breastmilk supply is well-established or regulated, which typically does not occur until six to 12 weeks postpartum. ${ }^{11}$

Upon returning to work, these mothers may face additional hurdles as a result of inadequate or unavailable lactation support, including a lack of dedicated time and space for expressing milk. Rigid and demanding teaching schedules, attendance at meetings and conferences, and limited access to conducive spaces to express breastmilk may inhibit the ability to do so on a regular schedule. Additionally, mothers may assume a lack of breastfeeding support at work and simply not inquire about the availability of needed resources. For practice-based faculty, these issues may be compounded by the COVID-19 pandemic, with new obstacles related to locating suitable lactation spaces and having adequate time to express breastmilk after de-robing from additional personnel protective equipment.

While federal legislation requires many employers to provide time and private space to express breastmilk at work, many workplaces do not offer appropriate accommodations. ${ }^{12}$ Healthy People 2020 recommendations include increasing the proportion of employers who provide worksite lactation programs to 38 percent from a baseline of 25 percent. ${ }^{13}$ Currently, 30 states have laws related to breastfeeding in the workplace. ${ }^{14}$ California boasts some of the most supportive laws, with a requirement for employers to provide all lactating employees, including those who are salaried, both time and private space in which to pump. ${ }^{15}$ A summary of state-specific breastfeeding laws with an accompanying ranking scale is available for reference online. ${ }^{15}$

Workplace challenges have the potential to be exacerbated by a lack of support from both peers and administration, as breastfeeding discrimination remains prevalent in many workplaces. ${ }^{16}$ Breastfeeding discrimination encompasses denying employees pumping breaks, refusing to provide private space for pumping, and even firing employees for requesting such breaks, and such objectionable practices have the potential to greatly impact affected female faculty. ${ }^{17}$ Research has suggested this cohort may be less likely to apply for positions that make it challenging to balance work and the concurrent responsibilities of motherhood, including breastfeeding. ${ }^{18}$ Described as "motherhood penalties" or "baby penalties," the consequences that child-bearing responsibilities have on the careers of women threaten to limit the number of female faculty in senior administrative positions. ${ }^{18}$ The current American Association of Colleges of Pharmacy (AACP) Profile of Pharmacy Faculty supports this trend, demonstrating a decline in female representation the higher one pursues promotion to professor and the trajectory to dean. ${ }^{8}$ In addition to impacting career advancement, these hurdles also place breastfeeding goals in jeopardy. Without appropriate support from employers, these mothers may choose to abandon breastfeeding prematurely.

\section{Considerations for Academic Institutions}

Given the variability in lactation support measures at both state and institutional levels, colleges of pharmacy are strongly encouraged to complete a needs assessment to identify barriers and opportunities for improvement. The following are targeted recommendations that may be implemented at colleges of pharmacy to promote the well-being of breastfeeding faculty and help ensure success as these individuals balance career and breastfeeding demands. ${ }^{3}$

\section{Creation of Supportive Policies}

Employers should develop and implement lactation support policies which ensure compliance with federal regulations and thoroughly articulate support for the well-being of their lactating employees. ${ }^{3}$ Such policies may be used to educate all employees about the importance of breastfeeding and assist in preventing and decreasing breastfeeding discrimination in the workplace. When developing lactation policies, employers should refer to Fair Labor Standards Act (FLSA) guidelines and clearly delineate the roles of both administration and faculty regarding lactation support services. They may also choose to include an accommodation request process for faculty, allow for arrangement of pumping times in advance, and make provisions which allow for flexibility in teaching schedules. The level of lactation support at colleges of pharmacy may follow legislative trends for the state, but colleges should strongly consider providing additional resources in states without poor support policies. It is important to note faculty may not be protected by federal and state laws as salaried individuals may be excluded from such protections. ${ }^{12}$

Colleges may find it beneficial to reference policies and resources from universities with strong lactation support systems in place. For example, The University of Northern Colorado's "Toolkit for Establishing Lactation Support on University and College Campuses" provides extensive guidance on lactation support considerations, including "How to Work with Rebuttals and Resistance When Establishing a Lactation Support Program", "How to Promote and Normalize 
Lactation On-Campus", a lactation support checklist, and resources for students and faculty. ${ }^{19}$ Additional helpful resources are referenced in Table 1.

To assist with supporting these initiatives, colleges may consider establishing internal and external partnerships. ${ }^{19}$ Such collaborations can help to maximize resources and optimize the effectiveness of policies and programs. Examples of external collaborators include local Le Leche Leagues and hospitals, while internal partners could include Human Resources and Diversity, Equity and Inclusion offices. Regarding funding, colleges may consider developing a specific lactation support program budget and applying for internal and/or external grant funding where available. ${ }^{19}$

\section{Flexibility in Work Schedules}

The COVID-19 pandemic saw the temporary creation of flexibility in work settings, including virtual instruction and meetings. For lactating faculty, this may have allowed for creative breastfeeding and lactating options and enabled these individuals to achieve breastfeeding goals with fewer barriers. With a current focus on a "return to normalcy," the continuation of this flexibility may be uncertain or undecided for some academic institutions. As a result of the pandemic, faculty are likely familiar with and better prepared to work from home, and institutions may choose to modify or adapt successful work-from-home models.

Institutions should consider allowing flexibility in work schedules, with the ability for employees to work from home, request reduced teaching loads, or teach online for a predefined time following the birth of a child. ${ }^{3}$ Employers should also be aware of the requirement to provide time "each time such employee has a need to express milk." 3 This will vary based on the age of the baby and the mother's milk supply. Early on, mothers will need to express milk every two to three hours, which equates to two to three pumping sessions during a typical eight-hour workday. The AAP has reported that a typical breastfeeding session lasts an average of thirty minutes. ${ }^{3}$ Expressing milk takes a similar amount of time, but employers should also account for the time needed to travel to and from the lactation space, set-up and clean equipment, and store milk. While employers are not required to pay for break time utilized to breastfeed or pump, it is considered best practice to not reduce pay. ${ }^{16}$

\section{Provision of Lactation Space and Resources}

The FLSA requires provision of an appropriate physical space for mothers to express milk until their child is one year of age. ${ }^{3}$ This space cannot be located within a bathroom and must be shielded from view and free from intrusion by coworkers or the public. ${ }^{3}$ Table 2 details required and recommended components of lactation spaces. Consideration should be given to creating dedicated lactation spaces near offices and classrooms and ensuring enough space is available should multiple employees need to pump simultaneously. If facilities and/or funding do not allow for reconstruction of existing space, a lactation 'pod' could be purchased to provide more lactation space. Lactation pods range in price from $\$ 9,000-\$ 22,000$ excluding shipping and installation costs. ${ }^{19} \mathrm{~A}$ less expensive option is installation of a simple privacy barrier, which could be utilized in multiple settings. ${ }^{19}$

Providing institution-wide resources, including creation of informational websites, seminars, and social media campaigns, may assist in creating a positive culture on pharmacy school campuses. Previous recommendations to mitigate faculty burnout have included the provision of free or reduced-cost health and wellness programs. ${ }^{1}$ Administrations should strongly consider providing lactating employees with breastfeeding references, lactation counseling, and access to a lactation consultant. ${ }^{3}$ Institutions may also consider the provision of onsite childcare services. Once services are established, feedback should be gathered regularly from employees to identify what is working and areas of improvement.

\section{CONCLUSION}

Outside of mitigating liability by complying with legal mandates, support of lactation practices may provide numerous benefits for academic institutions. These include financial incentives related to reduced employee health care costs, decreased absenteeism, and improved faculty retention rates. ${ }^{20}$ Additionally, providing lactation support promotes a more supportive workplace overall, with improved employee satisfaction, morale, and loyalty ${ }^{20}$ Finally, institutions may also benefit from improved public relations and organizational image.

As the Academy looks to improve the overall wellbeing of its members, it is incumbent upon academic institutions to consider the physical and psychological needs of its lactating faculty. Prioritizing provision of lactation support is an important initial consideration, and a vital first step in this process is normalizing conversations surrounding lactation and breastfeeding as parts of a natural component of faculty work-life balance. By providing institution-wide education on the benefits of supporting breastfeeding mothers in the workplace, breastfeeding discrimination may decrease as a more supportive work environment is promoted. Colleges of pharmacy should then consider completing a 
lactation support needs assessment to identify barriers to and opportunities for implementing support measures, and the Academy should determine where it stands regarding the Healthy People 2020 worksite lactation support goal. Institutions experiencing success may consider sharing ideas and experiences with the larger academic community. Information regarding the needs of breastfeeding faculty and the barriers to implementing lactation services would benefit the Academy as a whole, and successful lactation support campaigns may serve as an impetus to enact other family-friendly support measures that retain talented, vital faculty members. By placing this important issue in the forefront, the Academy can become a leader among institutions of higher education in the provision of workplace lactation support.

\section{REFERENCES}

1. Darbishire P, Isaacs AN, Miller ML. Faculty Burnout in Pharmacy Education. Am J Pharm Educ. 2020;84(7):ajpe7925. doi:10.5688/ajpe7925.

2. El-Ibiary SY, Yam L, Lee KC. Assessment of Burnout and Associated Risk Factors Among Pharmacy Practice Faculty in the United States. Am J Pharm Educ. 2017;81(4):75. doi:10.5688/ajpe81475.

3. Ladores S, Debiasi L, Currie E. Breastfeeding Women in Academia. Clinical Lactation. 2019; 10 (1): 10. doi: 1891/2158-0782.10.1.11

4. Global Strategy for Infant and Young Child Feeding. Geneva, Switzerland: World Health Organization. World Health Organization. 2003. Accessed October 2021. : https://apps.who.int/iris/bitstream/handle/10665/42590/9241562218.pdf.

5. Section on Breastfeeding, American Academy of Pediatrics. Breastfeeding and the use of human milk. Pediatrics. 2012;129(3):e827-e841. doi: https://doi.org/10.1542/peds.2011-3552.

6. Krol KM, Grossmann T. Psychological effects of breastfeeding on children and mothers. Psychologische Effekte des Stillens auf Kinder und Mütter. Bundesgesundheitsblatt Gesundheitsforschung Gesundheitsschutz. 2018;61(8):977-985. doi:10.1007/s00103-018-2769-0.

7. Fall 2020 Degrees Conferred- Profile of Pharmacy Students. American Association of Colleges of Pharmacy. 2020. Accessed October 2021. : https://www.aacp.org/research/institutional-research/student-applicationsenrollments-and-degrees-conferred.

8. Profile of Pharmacy Faculty. American Association of Colleges of Pharmacy. Accessed October 2021. : https://www.aacp.org/research/institutional-research/pharmacy-faculty-demographics-and-salaries.

9. OECD Family Database. Organization for Economic Cooperation and Development (OECD). Accessed October 2021. http://www.oecd.org/els/soc/PF2_1_Parental_leave_systems.pdf.

10. Family and Medical Leave Act. The US Department of Labor. Accessed October 2021. https://www.dol.gov/agencies/whd/fmla.

11. Le Leche League. Too Much Milk and Oversupply. Accessed October 2021. : https://www.laleche.org.uk/toomuch-milk-and-oversupply/\#howsupply.

12. Barraza L, Lebedevitch C, Stuebe A. The Role of Law and Policy in Assisting Families to Reach Healthy People's Maternal, Infant, and Child Health Breastfeeding Goals in the United States. Department of Health and Human Services, Office of Disease Prevention and Health Promotion (ODPHP); 4 May 2020. Accessed October 2021. Available from: https://www.healthypeople.gov/sites/default/files/MICH_report_2020.05.04_508_0.pdf.

13. Healthy People 2020 Breastfeeding Objectives. US Breastfeeding Committee. Accessed October 2021. Available from: http://www.usbreastfeeding.org/p/cm/ld/fid=221.

14. Breastfeeding State Laws. National Conference of State Legislatures. Accessed October 2021. Available from: https://www.ncsl.org/research/health/breastfeeding-state-laws.aspx\#State.

15. The Best States for Breastfeeding. Mamava. Accessed October 2021. Available from: https://www.mamava.com/mamava-blog/best-states-for-breastfeeding-moms.

16. How Companies Can Support Breastfeeding Employees. Harvard Business Review. Accessed October 2021. : https://hbr.org/2019/04/how-companies-can-support-breastfeeding-employees.

17. Morris L, Lee J, Williams J. Exposed: Discrimination Against Breastfeeding Workers. Accessed October 2021. : https://www.pregnantatwork.org/wp-content/uploads/WLL-Breastfeeding-Discrimination-Report.pdf.

18. Mothers in Academic Pharmacy: Tang S, Bostwick J, Wells T, Kraft S. Mothers in academic pharmacy. Curr Pharm Teach Learn. 2018; (10): 1168-1170.

19. UNC. Toolkit for Establishing Lactation Support on University and College Campuses. Accessed October 2021. : https://ksbreastfeeding.org/wp-content/uploads/2021/02/Lactation-Support-on-University-Campuses.pdf. 
20. Waite WM, Christakis D. Relationship of maternal perceptions of workplace breastfeeding support and job satisfaction. Breastfeed Med. 2015 May;10(4):222-7. doi: 10.1089/bfm.2014.0151.

Table 1. Workplace Lactation Support Resources

\begin{tabular}{ll}
\hline Resource & Available at: \\
\hline $\begin{array}{l}\text { Toolkit for Establishing Lactation } \\
\text { Support on University and College } \\
\text { Campuses: Using University of } \\
\begin{array}{l}\text { Northern Colorado as an } \\
\text { Institutional Model, 2nd Edition }\end{array}\end{array}$ & $\begin{array}{l}\text { https:/ksbreastfeeding.org/wp-content/uploads/2021/02/Lactation- } \\
\text { Support-on-University-Campuses.pdf }\end{array}$ \\
$\begin{array}{l}\text { Investing in Workplace } \\
\text { Breastfeeding Programs and } \\
\text { Policies: Employers Toolkit }\end{array}$ & https://web.uri.edu/worklife/files/BF_entire_toolkit_FINAL.pdf \\
$\begin{array}{l}\text { Breastfeeding Support in the } \\
\text { Workplace: Resource Toolkit }\end{array}$ & $\begin{array}{l}\text { http://www.nhbreastfeedingtaskforce.org/pdf/NHBF_Workplace_Toolk } \\
\text { it.pdf }\end{array}$ \\
$\begin{array}{l}\text { The Business Case for Breastfeeding } \\
\text { https://owh-wh-d9-dev.s3.amazonaws.com/s3fs- } \\
\text { public/documents/bcfb_easy-steps-to-supporting-breastfeeding- } \\
\text { employees.pdf }\end{array}$ \\
\hline
\end{tabular}

Table 2. Components of Lactation Spaces

\begin{tabular}{l|l}
\hline Required Components & Recommended Components \\
\hline Chair/seating & Comfortable chair with good back support \\
Surface for equipment & Comfortable temperature \\
Electrical outlet & Multiple electrical outlets \\
& Lighting which can be dimmed \\
& Sink to clean supplies \\
& Clean, designated refrigerator, freezer, or other cold location to \\
& store breast milk \\
& Door that locks or keypad entry \\
& Clock \\
& Wall mirror \\
& Sanitizing wipes and other cleaning supplies \\
& Educational resources \\
\hline
\end{tabular}

